Gestión y Estrategia

Management and Strategy

Gestão e Estratégia
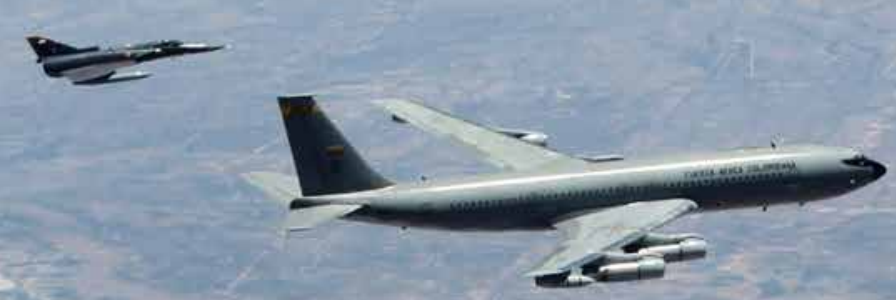

\title{
Asedio a Güepí: Fuerza Aérea Colombiana, mirada a una operación trascendental ${ }^{1}$
}

Siege of Güepí: Colombian Air Force, look at a transcendental operation²

Cerco a Güepí: Força Aérea Colombiana, olhar para uma operação de transcendental ${ }^{3}$

Abraham Ortiz Miranda ${ }^{4}$

Fuerza Aérea Colombiana. Bogotá, Colombia

\section{CIENCIA Y PODER AÉREO}

ISSN 1909-7050 / E- ISSN 2389-9468 / Volumen 13 / Número 2 / julio-diciembre de 2018/ Colombia /pp. 68-76 Recibido: 20/02/2018

Aprobado par evaluador: 15/04/2018

Doi: $10.18667 /$ cienciaypoderaereo.602 
Para citar este artículo:

Ortiz, A. (2018). Asedio a Güepí: Fuerza Aérea Colombiana, mirada a una operación trascendental. Ciencia y Poder Aéreo, 13(2), 68-76. doi: 10.18667/cienciaypoderaereo.602

' Artículo resultado de una reflexión exploratoria del conflicto colombo-peruano asociado al Grupo de Investigación Análisis en Contexto. DICOP. Fuerza Aérea Colombiana.

${ }^{2}$ Article resulting from an exploratory reflection of the Colombian-Peruvian conflict associated with the Research Group Analysis in Context. DICOP. Colombian Air Force.

${ }^{3}$ Artigo resultado de uma reflexão exploratória do conflito colombiano-peruano associado à Análise de Contexto do Grupo de Análises. DICOP. Força Aérea Colombiana.

${ }^{4}$ Profesional en Historia de la Universidad Nacional. Oficial historiador Fuerza Aérea Colombiana. Correo electrónico: aortizmiranda@gmail.com
Resumen: Abandonada a su suerte, fue en la zona de fronteriza del trapecio amazónico colombiano donde se decidió el destino de un trance mucho mayor: el conflicto con el Perú. Impulsado por la presencia de aventureros y empresarios en la región, el gobierno central peruano pretendió dislocar la integridad nacional colombiana. No obstante, tales objetivos de ocupación ilegal del territorio colombiano se vieron coartados por el hecho de la victoria decisiva que conquistó el poder aéreo colombiano en el bastión de Güepí. Fueron las dinámicas sociales y de comportamiento humano y castrense que se gestaron al interior de la institución, las que permitieron que la Fuerza Aérea Colombiana coadyuvara a mantener el control del Estado a nivel nacional, y así cumplir los objetivos constitucionales.

Palabras clave: Fuerza Aérea Colombiana, poder aéreo militar, Amazonas, Güepí, victoria decisiva.

Abstract: Abandoned to its fate, it was in the border area of the Colombian Amazon trapeze where the fate of a much greater trance was decided: the conflict with Peru. Driven by the presence of adventurers and entrepreneurs in the region, the Peruvian central government sought to dislocate Colombia's national integrity. However, these objectives of illegal occupation of Colombian territory were hampered by the fact of the decisive victory of Colombian air power in the bastion of Güepí. It was the social dynamics and human and military behavior that were developed within the Institution, which allowed the Colombian Air Force to help maintain control of the State at the national level, thus fulfilling the constitutional objectives.

Keywords: Colombian Air Force, Military Air Power, Amazon, Güepí, Decisive Victory.

Resumo: Abandonado ao seu destino, foi na área fronteiriça do trapézio amazônico colombiano que se decidiu o destino de um transe muito maior: o Conflito com o Peru. Impulsionado pela presença de aventureiros e empresários na região, o governo central peruano buscou deslocar a integridade nacional colombiana. No entanto, tais objetivos de ocupação ilegal do território colombiano, foram prejudicados pelo fato da vitória decisiva que conquistou o poder aéreo colombiano no bastião de Güepí. Foi o comportamento social e humano e a dinâmica militar que se desenvolveu dentro da Instituição, o que permitiu que a Força Aérea Colombiana ajudasse a manter o controle estatal em nível nacional, cumprindo assim os objetivos constitucionais.

Palavras chave: Força Aérea Colombiana, Força Aérea Militar, Amazônia, Güepí, Vitória Decisiva. 


\section{Introducción}

El Estado-nación colombiano ha sido presa de periodos de violencia desde el mismo inicio del siglo XX, los cuales han pretendido quebrantar su cuerpo institucional y hasta su integridad nacional. Un ejemplo histórico de lo anterior es el planteamiento de objetivos que actores trasnacionales gestaron para ampliar sus propios territorios a costa de la desintegración del territorio nacional, trastornando así la cotidianidad de la población del sur de Colombia. A priori a los estallidos de violencia endógena que marcaron el siglo XX, poblaciones amazónicas fronterizas se vieron temporalmente desintegradas del territorio colombiano al ser invadidas por tropas peruanas, las cuales pretendían usufructuar rentas sobre la tierra ilegítimamente ocupada el 1 de septiembre de 1932. Tal invasión fue un pilar más para gestar épocas que situaban a los ciudadanos en una constante perspectiva de peligro, planteándose la duda sobre si el leviatán colombiano realmente era tal, ya que se empezaba a perder el monopolio legítimo de las armas por parte de las administraciones centrales' (Di John, 2010, pp. 49-50).

Un factor esencial para que Colombia no se fragmentara por motivo de su conflicto internacional en la tercera década del siglo pasado, es el hecho de que la Fuerza Aérea Colombiana tuvo bajo su mando el liderazgo de operaciones trascendentales que permitieron la llegada del fin de dichas luchas. Siguiendo siempre las directrices establecidas desde el Estado por intermedio del comando general de las fuerzas militares, el potencial y las facultades de la Fuerza Aérea Colombiana relucieron en las múltiples operaciones que debió cumplir, bien fuera de respuesta inmediata a ataques de grupos armados extranjeros usando grandes destacamentos, o una decisión gubernamental, logrando una victoria decisiva desde el aire.

\section{Marco conceptual}

Para una mayor comprensión del contexto, tal concepto de victoria decisiva necesita de ciertas precisiones, siendo la primera de ellas ratificar que la implementación de la fuerza militar es un instrumento de decisión usado por los estados (definición de Estado, ver nota 3). En un segundo estadio, la victoria decisiva en lo militar conduce a decisiones políticas, considerando siempre múltiples opciones aceptables:

En este sentido, la victoria decisiva puede manifestarse en tres niveles: a) el operacional, cuando la victoria decide el resultado de una campaña; b) a nivel estratégico, cuando la victoria decide

1 Aquí se sigue un entendimiento de la falencia estatal desde las premisas maquiavélico/weberiano, tal y como se observa más adelante. quién gana en lo militar; c) la victoria decisiva a

nivel político. (Marín et al., 2017, p. 46)

La victoria decisiva se conquistó por motivo que la Fuerza Aérea Colombiana convenció a los opositores del Estado alzados en armas, a reevaluar su actuar. La base de dicho logro tuvo su germen en las acciones militares con las que la Fuerza hizo que el bando peruano considerara el costo-beneficio de no realizar lo que Colombia determinaba. La implementación de lo anterior se llevó a cabo por parte de la institución castrense aérea, a partir de disuadir a los grupos armados extranjeros de no realizar cruzadas inaceptables y al compelerlo de cambiar su comportamiento (Losada, 2014, p. 13).

\section{Objetivos}

Para lograr entender dichas conquistas y logros meritorios de la Fuerza Aérea Colombiana que coadyuvaron a mantener el control del Estado a nivel nacional, y así cumplir los objetivos constitucionales, es necesario buscar la raíz histórica de estas. Una pertinente identificación de las estructuras temporales que la Fuerza Aérea Colombiana heredó del conflicto colombo-peruano, hará relucir aquellas dinámicas sociales y de comportamiento humano y castrense que permitieron que el poder aéreo nacional reinara en el sur del país. Sin el desarrollo a priori de tales conductas y accionares por parte del personal que componía la aviación militar colombiana, el impacto del poder aéreo nacional durante el desarrollo del conflicto hubiera sido muy variable e ínfimo.

No obstante, al entrar en el detalle de las mencionadas estructuras temporales que surgieron en dicha época, se vuelve asequible un conocimiento cabal del impacto que el poder aéreo militar colombiano tuvo en el desarrollo del conflicto con el Perú. Las decisiones que los integrantes del arma aérea tomaron en su momento, en el teatro de operaciones del trapecio amazónico, estuvieron completamente influenciadas por los motivos y causales cambiantes que los obligaba a estar en perspectiva beligerante; de allí que el estudio de las mencionadas mociones sea pertinente para determinar el alcance que tuvo la aviación militar colombiana en los momentos de conflicto internacional.

\section{Marco teórico}

Comprender la victoria decisiva desde el aire que gestó la institución, significa generar un eficaz y compresible conocimiento de sus estructuras temporales, de sus "itinerarios ya recorridos, de los valores antiguos, de las experiencias vividas", a razón que una entidad castrense como la aquí estudiada, "es siempre un pasado, de este modo, un cierto pasado vivo" (Goberna, 2003, p. 218). Son las continuidades temporales establecidas y construidas a través de casi un siglo de existencia las que han dado paso a una estructura, 
a un indudable "ensamblaje, una arquitectura; pero, más aún, una realidad que el tiempo tarda enormemente en desgastar y en transformar", trascendiendo el simple hecho de ser nada más que una organización (Braudel, 2006, p. 8).

Es allí donde reside la importancia de tales acontecimientos que traspasan las conciencias de los contemporáneos para ser más que una explosión, una llamarada que los obnubila. Testimoniando sobre movimientos muy profundos, los mismos deben estar cargados de una serie de significaciones y relaciones (Braudel, 2006, p. 4), que sean capaces de presentar consecuencias de tal magnitud que se aproximen al reloj de tiempo de Fernand Braudel: "primero, del acontecimiento a la estructura, y, después, de las estructuras y de los modelos al acontecimiento" (Braudel, 2006, p. 32).

En otras palabras, son de suma importancia solo las operaciones aéreas que representan un tipo de acontecimiento que entra en dialéctica con aquella arquitectura que le rodea, para romper con "los viejos ciclos y con las tradicionales costumbres" (Goberna, 2003, p. 218) del mundo castrense de ese entonces. Es solo aquella intervención que realmente señala un "cambio", "una fase nueva", destacando por sí mismas (Goberna, 2003, p. 218), por motivo de gestar nuevas estructuras que se vuelvan casi imperecederas al trasegar del tiempo, relacionando el pasado con el presente en "un continuo ir y venir" (Goberna, 2003, p. 219). Finalmente, se debe tener en la mirilla solo aquella operación trascendental realizada por la Fuerza Aérea Colombiana que logró la construcción de realidades que han durado "tanto tiempo que pueden parecer inmutables, aunque también varían lenta e imperceptiblemente" (Goberna, 2003, p. 221), sobresaliendo "entonces las grandes permanencias o semipermanencias, tanto conscientes como inconscientes" de la institución (Goberna, 2003, p. 222).

Por lo tanto, una operación que realizó la Fuerza Aérea Colombiana en pro de mantener la integridad nacional y la legitimidad del Estado, para así cumplir los objetivos constitucionales, y que marcó un hito trascendental en la generación de doctrina dentro de la institución, perdurando hasta hoy día, es la batalla de Güepí, enmarcada en el conflicto colombo-peruano de inicios del siglo XX, tal asedio construyó en un primer estadio la plataforma de tecnificación, profesionalización y de reacción oportuna y precisa que ha caracterizado a la Fuerza hasta hoy en día, además de ser la primera operación conjunta realizada por las fuerzas militares colombianas.

\section{La batalla de Güepí}

\section{La previa al asedio}

Aquél asedio conjunto de 8 horas sobre Güepí decidió el destino de los territorios sureños colombianos, lugares de frontera no tenidos en cuenta por el Estado colombiano a inicios del siglo XX. Sobre estas locaciones se decidió el destino de un trance mucho mayor: el conflicto con el Perú.

A diferencia de los 2.220 kilómetros de frontera acordados y delimitados en 1891 en la región de la Orinoquía entre Colombia y Venezuela, para finales del siglo XIX e inicios del XX estaban pendientes los límites internacionales con Brasil, Perú y Ecuador. La situación sobre el trapecio amazónico se vio acentuada por razón de que la explotación del caucho se volcó en el centro de gravedad de los distintos gobiernos y los grandes emporios industriales. Es allí donde aparecen en el radar personajes como Julio César Arana, "quien en 1910, y sobre la base de sus estaciones caucheras en Colombia, ya era uno de los principales productores suramericanos" (Palacios, 2002, p. 514).

Pugnando la soberanía colombiana y el modus vivendi establecido entre Colombia y Perú para el año de 1906, el convenio limítrofe de 1907 de Colombia y Brasil y el acuerdo establecido entre Ecuador y Colombia para el año de 1916, la Casa Arana² fue denunciada por delitos tales como "esclavitud, peonaje por deudas y explotación sexual de mujeres" (Palacios, 2002, p. 515), sobreviviendo a todas las investigaciones que se realizaron en su contra y hasta a una encíclica papal. Con lo anterior, la empresa más grande de explotación del caucho se transfiguró en la punta de lanza de los empresarios y aventureros extranjeros, transformándose en una prueba del gobierno central peruano sobre su posesión del trapecio amazónico colombiano.

Si bien uno de los motivos de la pugna se debía a razón de la incomunicación casi total del gobierno central colombiano con estas regiones, esta se vio acrecentada, en un primer momento, con la derrota de un contingente de 70 soldados a manos de tropas peruanas en la Chorrera; y en un segundo estadio, por motivo del fortalecimiento político y económico de Arana. Estando detrás de todos los movimientos peruanos sobre territorios colombianos, "Arana y las elites de Loreto no se dieron por vencidos", llegando a patrocinar un "grupo armado de policía y civiles peruanos que, sin disparar un solo tiro, coparon la guarnición colombiana de Leticia", el 1 de septiembre de 1932 (Palacios, 2002, p. 517).

Incluyéndose el desconocimiento del tratado fronterizo firmado en el año de 1922 entre Colombia y Perú, el gobierno de Luis Miguel Sánchez Cerro "reconoció la "junta patriótica" establecida en Leticia", dando así inicio al conflicto colombo-peruano (Palacios, 2002, p. 517). Dos de las

2 Empresa de Julio César Arana, más tarde conocida como la Peruvian Amazon Rubber Company, registrada en Londres y en la que "participaban capitalistas del reino" (Palacios, 2002, p. 515). 


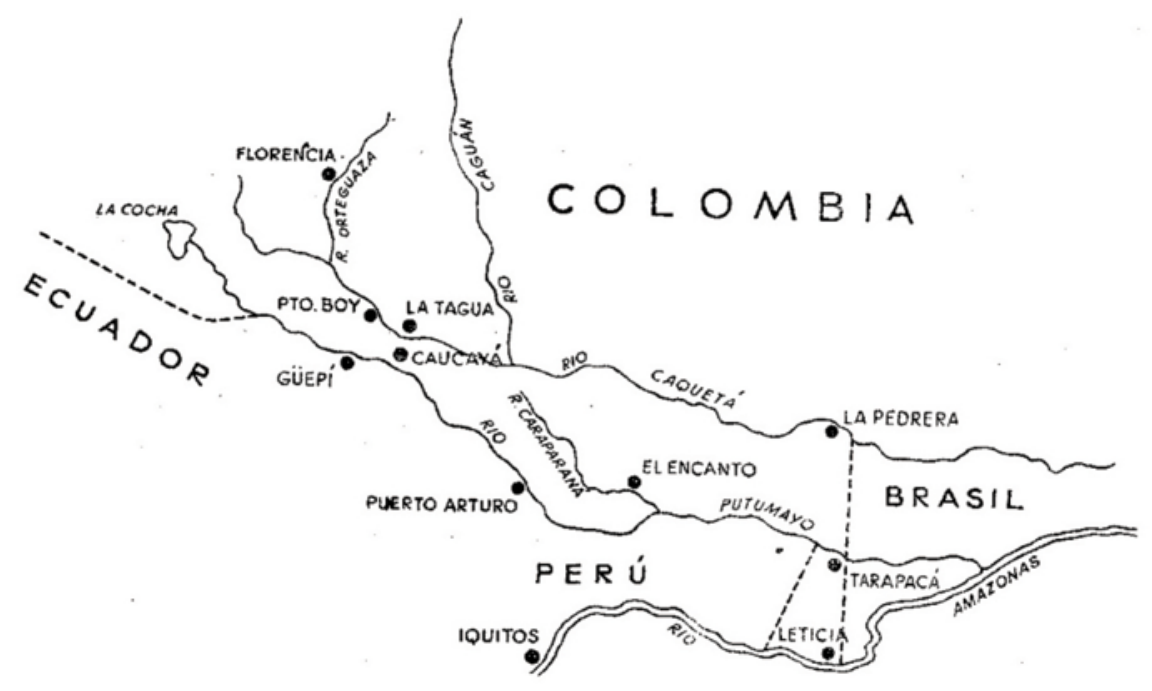

Figura 1 Aplicabilidad del modelo

Fuente: Croquis del Sur de Colombia-Conflicto con el Perú. (Boy, 2009, 203).

batallas cruciales que ayudaron a solventar la problemática de Colombia con su vecino del sur, fueron la batalla de Tarapacá y la batalla de Güepí. Si bien el asedio conjunto sobre las tropas peruanas apostadas en Güepí marcó la pauta militar para negociar el fin del conflicto en la sociedad de naciones ${ }^{3}$, no hay que perder de vista que fue en Tarapacá donde se comenzó a recuperar el territorio perdido a manos peruanas. Si bien fue en tal asedio sobre dicha población colombiana, aledaña a Leticia, donde se logró la victoria por medio de un bombardeo contraofensivo, fue en Güepí donde la aviación colombiana conquistó la supremacía aérea necesaria para convencer a las fuerzas militares del Perú a reevaluar su actuar; con sus acciones, la Fuerza Aérea Colombia puso en consideración de dichos grupos el costo-beneficio de no realizar lo solicitado por la institucionalidad colombiana, como se examina a continuación.

\section{La hora de la verdad...}

Mostrándose displicente y escéptico durante su estancia en Manaos, el general Alfredo Vásquez Cobo llegó a darle a la aviación militar colombiana de la década de 1930, la relevancia y estima que esta merecía después de ver los resultados de acciones tales como la batalla de Tarapacá del 15 de febrero de 1933. No obstante, surge la incertidumbre de cuáles fueron las razones que motivaron tal cambio.

3 Pasados casi dos meses exactos de la batalla de Güepí, Herbert Boy recibe un radio en donde el presidente Olaya Herrera le indicó la suspensión de las hostilidades luego que el Perú hubiese aceptado "la fórmula de arreglo que había sido propuesta para solucionar el conflicto" (Boy, 2002, p. 232).
Ubicada sobre el río Caquetá, la base de Puerto Boy se construyó a razón de la distancia mediada entre la base de Palanquero y el teatro de operaciones del sur durante el conflicto con el Perú. Las operaciones militares en el sur hacían impositivo el establecimiento de una base aérea situada a distancia prudencial de la frontera colombo-peruana (Villalobos, 1993, p. 56).

Edificada con el fin de proveer protección aérea a las distintas guarniciones ubicadas en el trapecio amazónico colombiano, la base de Puerto Boy contó con la facilidad de extensas y amplias aguas rectilíneas del río Caquetá al ser ubicada en frente de Caucayá. Gozando con riberas que estaban varios metros sobre el nivel de las aguas, y poseyendo capas vegetales suficientes para el autoabastecimiento por medio de la agricultura ${ }^{4}$, los medios de subsistencia de este paraje distaba mucho de los que poseía la escuela de formación en aviación militar y sus planicies, o de los de la base de Palanquero y su centralidad en el territorio nacional:

La carencia de medios y de materiales y la ingente dificultad para llevar estos elementos desde el interior del país, dada la absoluta ausencia de vías de comunicación, obligaban a acometer un proyecto de instalaciones rústicas cuya urgencia no admitía pérdida de tiempo. (Villalobos, 1993, p. 56)

$4 \mathrm{Al}$ acuatizar vimos que en efecto la tierra se esponjaba, elevándose a unos quince metros de altura sobre el nivel del río, y era un lugar seco y adecuado para nuestros proyectos (Boy, 2009, p. 204). 


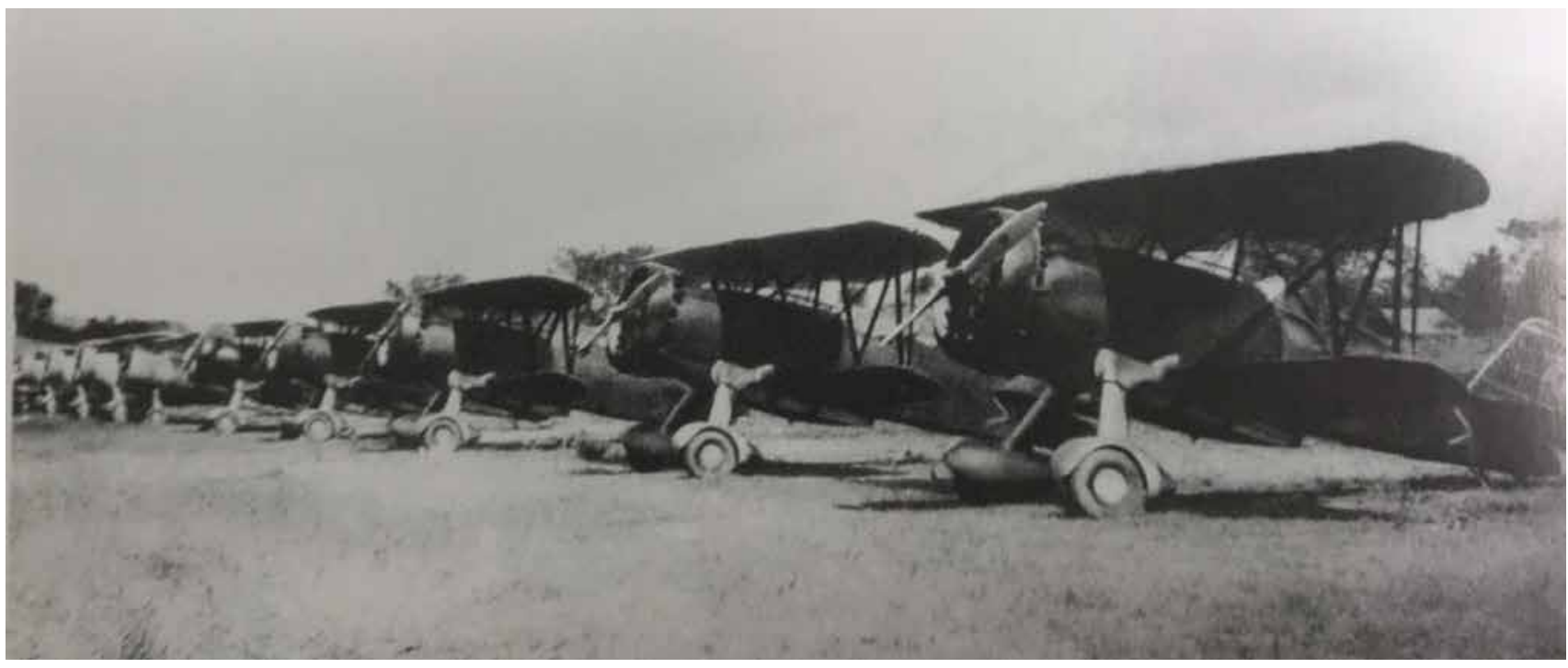

Figura 2. Flotilla de Hawk II F-11

Fuente: Boy (2009, p. 237)

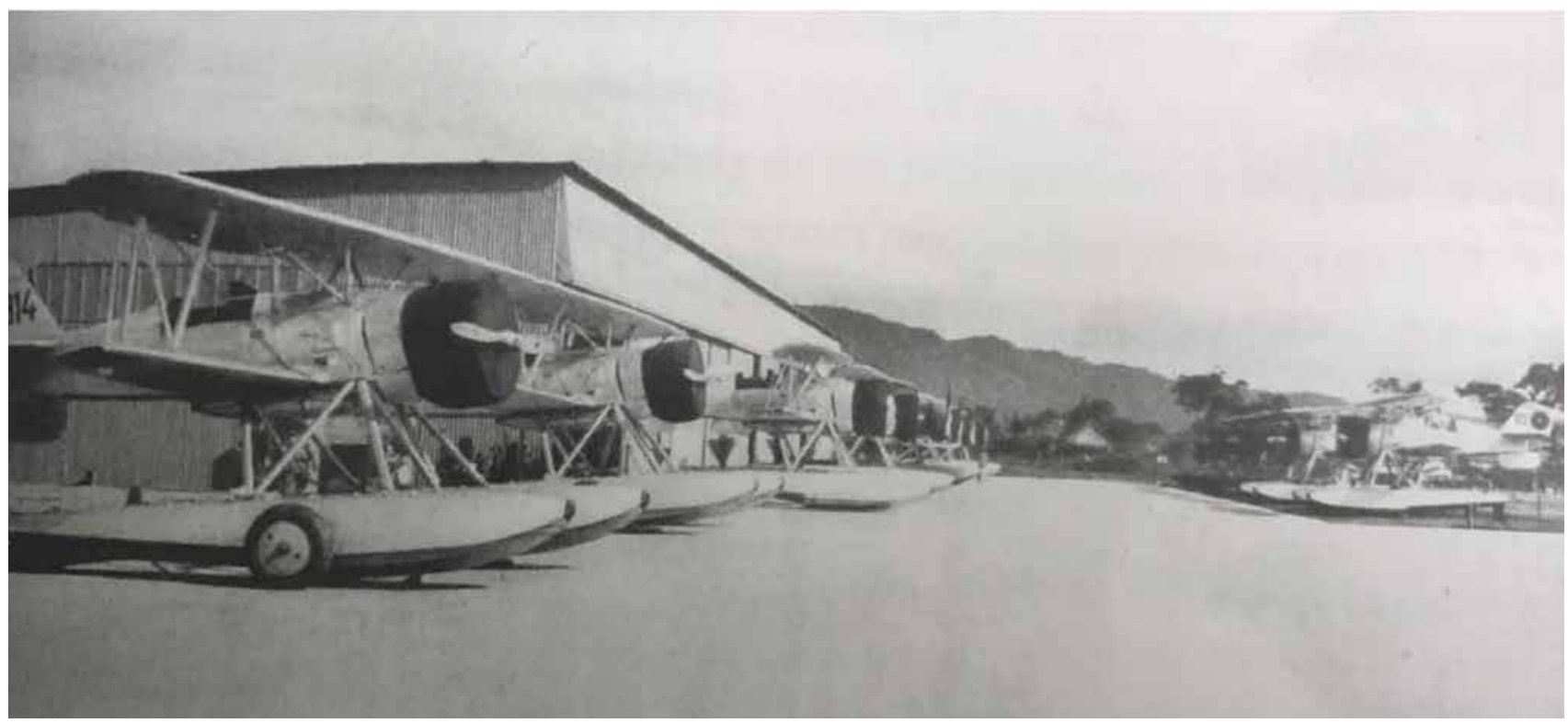

Figura 3. Flotilla de Osprey C-14

Fuente: Boy (2009, p. 238)

A tal terreno selvático se le sumaba una serie de enemigos contra los cuales tuvieron que luchar los hombres que participaron en la campaña del sur. Considerada como una prisión para las tropas, la selva amenazaba la existencia dada la cantidad de pantanos y miasmas que habitaban en esta, enfermando a cada humano que en ella habitara a razón que doblegaba de forma rápida su resistencia. No obstante, dichos desafíos no fueron piedra de tropiezo para que Puerto Boy no pudiera ser dotada con rampas para los aviones que intervinieron en el conflicto; ranchos y casas de madera, bodegas para materiales, alojamientos para tropas, estación de radio, muelle-atracadero, puesto de sanidad, comedores, cuartel, servicios sanitarios, abastecimiento de agua y sementeras y hortalizas para la supervivencia.

La infraestructura mencionada soportó y proyectó a la victoria sobre el bastión de Guëpí. El parque aeronáutico colombiano destinado para el conflicto, compuesto por 11 aviones de ataque: seis Hawk II F-11, tres Wild X y dos Osprey C-14 de caza y bombardeo (Fuerza Aérea Colombiana, 2014). 
Vale resaltar que los indígenas de Curiplaya otorgaron gran apoyo para la realización de un proyecto de tal magnitud, como lo era la base hidroaérea de Puerto Boy. Los nativos tuvieron a cargo la misión de realizar la limpieza de la selva y la construcción de toda la infraestructura que contemplaba la unidad, edificándola en menos de un mes. La ayuda de la comunidad amazónica no solo se limitó a lo vislumbrado, sino que se extendió a tareas tales como el abastecimiento de alimentos o la guía y localización de las tropas de la aviación militar colombiana en la zona (Boy, 2009, pp. 204-206).

A su vez, las fuerzas peruanas no se quedaban atrás en el conflicto; las tropas comenzaron a robustecer sus posiciones en Güepí, teniendo en mente el obstaculizar el paso fluvial colombiano entre Puerto Asís y Caucayá. Haciendo presencia con varias embarcaciones armadas arriba de Puerto Arturo, 140 hombres se movilizaron a la guarnición peruana de Pantoja para así reforzar Güepí. Motivadas por tales movimientos, las fuerzas colombianas fueron engrosadas con un total de 992 hombres que garantizaban acciones sobre Caucayá, El Encanto, Puerto Ospina, Chavaco y Puerto Asís, siendo aprovisionados constantemente por la aviación militar. Con estas acciones, las tropas peruanas vigorizaron el bastión de Güepí al construir zanjas para tiradores y puesto de observación, contando con el apoyo de la base aérea del alto Napo.

Seleccionada la posición de Güepí, partiendo de la perspectiva del Estado de disminuir las hostilizaciones sistemáticas en contra de sus embarcaciones en la cuenca amazónica, el 26 de marzo de 1933 se llevó a cabo la batalla sobre esta. Tal decisión se vio motivada por "la necesidad de despejar la amenaza adversaria en aquellos sitios del río donde el enemigo tenía mayor posibilidad de ejercer control y obstruir el aprovisionamiento" (Villalobos, 1993, p. 66). Aunque aquella determinación fue meditada por los altos mandos, el asedio sobre Güepí sufrió varios retrasos, debidos a la gestión jurídica llevada a cabo por el delegado de Colombia ante la Liga de las Naciones, "llovían órdenes y contraórdenes procedentes de Bogotá de acuerdo con el giro de las conversaciones de Ginebra, y la tropa padecía el tedio de la inacción, que es fatal para ejércitos en campaña" (Boy, 2009, p. 230).

La primera orden de ataque llegó el 13 de febrero de 1933, cuando se intensificaron los hostigamientos por parte de las tropas peruanas a la navegación colombiana en el alto Putumayo. A la par que la Liga de las Naciones fallaba parcialmente a favor de las premisas colombianas, "el Comité del Consejo de la Liga, encargado de informar sobre el caso de Leticia, no puede comprender cómo estando el puerto de Tarapacá dentro del territorio colombiano, había allí guarniciones militares del Perú" (Villalobos, 1993, p. 66). Por otro lado, el general Vázquez Cobo trasmitía un ultimátum de rendición a las fuerzas peruanas que estaban dentro del territorio nacional. Tal declaratorio vio la luz ya que en aquellos días la aviación militar peruana emprendió acciones de bombardeo sobre los buques de la Expedición Amazonas, estando ellos aún en aguas brasileñas. La situación se vio agravada como consecuencia del asalto que se produjo a la sede de la Legación de Colombia en la capital de Lima. Aunque la gestión militar tenía clara su proyección sobre el conflicto, el estadio político viraba sus manijas a partir de lo vivenciado en la Liga de las Naciones. Resultado de lo anterior es la emisión de la primera contraorden del 17 de febrero, aplazando toda acción militar en razón del sentido favorable que habían tomado las negociaciones entre Colombia y Perú.

Entretanto, se habían entablado gestiones en Ginebra, ante la Liga de las Naciones; el doctor Eduardo Santos, como delegado de Colombia, procuraba por todos los medios hacer triunfar las tesis jurídicas de la Cancillería de San Carlos, demoliendo la argumentación de los peruanos. No podía entrabarse la gestión de Ginebra emprendiendo acciones militares que debilitaran nuestra posición jurídica, pero tampoco podía descuidarse la preparación de un ataque sobre las guarniciones peruanas, en el caso de que las negociaciones fracasaran. (Boy, 2009, p. 230)

Olvidando el escenario de negociaciones, aeronaves peruanas aumentaban su actividad a lo largo del río Putumayo, llegando incluso a considerar ocupar un islote colombiano aledaño a Chavaco, obligando a los militares colombianos a trabar combate para repelerlos y evitar tal pretensión. Según una información emitida por el coronel Roberto D. Rico, "los peruanos han atacado nuestras canoas procedentes de Puerto Asís sin lograr hacer blanco. Hostilidad interrumpe prácticamente nuestras comunicaciones creando grave situación. Espero órdenes" (Villalobos, 1993, p. 69).

Tales hostilidades por parte del lado peruano motivaron una segunda orden de ataque el 22 de febrero. No obstante, y por segunda vez, dicha orden no se efectuó, teniendo como causa el hecho de que el gobierno peruano venía flexibilizando su férrea posición en la Liga de las Naciones, "sin duda, a esta modificación contribuyó en alto grado el descalabro sufrido por las fuerzas [peruanas] que hubieron de abandonar Tarapacá y la inminencia del ataque colombiano contra Güepí, previsible por las concentraciones en Chavaco" (Villalobos, 1993, p. 70). Lo anterior generó que se detuviera todo asedio contra los navíos colombianos en el alto Putumayo. El cese al fuego en cuestión fue 
respondido por el gobierno colombiano al detener la operación el día 28 de febrero.

Finalmente, la ofensiva contra Güepí se desarrolló el día 26 de marzo de 1933. Sin embargo, la operación tenía que sobreponerse a un impase más para poder efectuarse: el general Vásquez Cobo, quien durante su paso por Manaos se manifestó de manera apática frente a la aviación militar. Al momento del movimiento de las flotas aéreas apostadas después de la batalla sobre Tarapacá, el general Vásquez Cobo comenzó a valorar el poder aéreo, a tal punto que, paradójicamente, no permitía ningún movimiento sino era autorizado por él mismo.

Veía que nuestra presencia en Tarapacá ya no era indispensable, puesto que la situación se había fortalecido y los barcos permanecían como centinelas anclados en la orilla. Además, se necesitaba el concurso de la aviación en el alto Putumayo, para otras operaciones militares tendientes a despejar de enemigos las orillas del río.

Expuse al general Vásquez Cobo estos puntos de vista, pero él, que en Manaos se había mostrado tan displicente y escéptico cuando le hablaba de nuestra aviación, ahora exageraba su importancia y por ningún motivo permitía que la dejara abandona en mitad de la selva. Un día dirigió un radio al presidente Olaya Herrera, con estas palabras: si los aviones no pueden venir a auxiliarnos contra los aviadores peruanos, en breves días nuestra situación será muy grave (Boy, 2009, p. 227)

No obstante, dicho comportamiento fue solventado por motivo que desde el Estado Mayor General se emitió la orden de movilizar la aviación al alto Putumayo, a raíz de que allí era menester tenerla por las razones anteriormente aducidas, permitiéndose el asedio sobre Güepí.

Frente a tal operación, la aviación militar presentaba la orden específica de ser la primera en entablar combate para ablandar las posiciones de su contrincante, brindando apoyo constante al ejército.

Bombardeará las posibles fortificaciones del enemigo, especialmente las que se encuentran detrás de la margen derecha del río, y no se retirará de su radio de acción sino cuando haya constatado que nuestra infantería ha hecho el paso del río e iniciado combate formal. Quedará luego en vigilancia a fin de batir probables aviones enemigos que se presenten y para recibir nuevas tareas que los cambios de situación demanden. (Villalobos, 1993, p. 71)
Es así que a las 08:30 horas decolaron las primeras aeronaves desde la base de Puerto Boy, para hacer entrega de su armamento sobre el bastión de Güepí. Durante un periodo de 8 horas, las 11 aeronaves destinadas para este asedio obligaron a las tropas del contrincante a replegarse a una segunda línea de senderos y zanjas que facilitaban su escape a la población de Pantoja, desviando siempre la atención del antagonista de las maniobras que la Armada y el Ejercito realizaban sobre la posición en cuestión. No obstante, la resistencia peruana cedió marcando un triunfo para Colombia hacía las 16:30 horas, ondeando sobre Güepí el pabellón nacional, "se acercaban rápidamente a las orillas, y mientras los aviones castigaban la guarnición enemiga, se llevó el desembarco por dos puntos distintos. La operación fue perfecta por la serenidad y la rapidez con que actuaron las tropas" (Boy, 2009, pp. 230-231).

Fue una victoria decisiva y clara la que se obtuvo en aquella ocasión, a razón que diez bajas se presentaron del lado peruano, sin contar que las tropas colombianas retuvieron como prisioneros a 24 combatientes, más otros dos que quedaron heridos (Villalobos, 1993, pp. 71-72) Con lo anterior, a diferencia de la batalla de Tarapacá, el asedio sobre Güepí se convirtió en una operación trascendental.

El influjo que se recibió de las doctrinas militares aéreas de países como Francia, Suiza, Alemania y Estados Unidos ${ }^{5}$ en los primeros años de formación de la aviación militar colombiana, claramente marcaron uno de los pilares de victoria sobre Güepí. Fue el proceso de estandarización al que se vio sometida tanto la instrucción como la formación de los aviadores y mecánicos colombianos, las que rindieron frutos en la campaña del sur:

Se abandonaron las prácticas desarrolladas empíricamente, tanto en el área de mantenimiento, como en el de vuelo primario. Se revisaron funciones y roles del personal militar y de instructores, procurando reducir las responsabilidades administrativas de estos últimos a fin de dirigir los esfuerzos a incrementar el número de horas de instrucción en tierra y en vuelo. Aunque los manuales siguieron siendo pocos, se procuró traducirlos lo mejor posible al español y elaborar otros, siguiendo el lineamiento de los existentes e incorporando la experiencia que se había adquirido en los años anteriores. (Peña, 2015, p. 30)

5 Se menciona este país a razón del "ingreso al escalafón militar de aviadores y mecánicos de aviación formados en el exterior", que coadyuvaron a complementar las tareas de las misiones extranjeras per se (Peña, 2015, p. 26). 
A nivel nacional, tal demostración del poder aéreo puso en evidencia la necesidad de contar con una flota de aeronaves capaz de hacer desistir al contrincante de sus premisas ofensivas, a más de generarse un aumento drástico en la capacidad operativa de la aviación militar. Colombia inició el conflicto del sur contando nada más que con un destacamento de tan solo 16 aviones, siendo que para el final de las hostilidades, el 25 de mayo de 1933, el número de aeroplanos se multiplicó hasta llegar a ser más de 60. Lo mismo ocurrió con el personal de la aviación militar, ya que el grueso de las filas llegó a contar con 27 pilotos y 37 mecánicos, a diferencia de los 12 pilotos y 17 mecánicos que estuvieron presentes al inicio del conflicto (Forero, 1994, pp. 51-52).

\section{Batalla de Güepí: operación trascendental}

Haciendo un recuento de todos los percances y contratiempos que tuvo la aviación militar para poder realizar la operación sobre el bastión de Güepí, es de notar que, por la profesionalización de la técnica y la instrucción de la aviación del momento, y por el imperante papel que los comandantes de las fuerzas militares de la época le otorgaron a la aviación militar, es que la Batalla de Güepí se nombra una victoria decisiva desde el aire.

A la par, la construcción de Puerto Boy y la adquisición y modernización de las flotas de aeronaves disponibles para el momento del conflicto, dan cuenta de la reflexión que hizo el control central colombiano para adquirir una victoria decisiva desde el aire en los niveles operacional y estratégico. Bastó la simple hazaña de Güepí para determinar el resultado de la campaña y la superioridad militar, las cuales coadyuvaron a gestar las derivaciones políticas negativas a las pretensiones peruanas sobre el trapecio amazónico en los tribunales de la Sociedad de Naciones, fallando a favor de Colombia.

Lo anterior no hubiera sido posible sin antes tener en cuenta que el Estado Mayor General de aquel tiempo cae en razón de la flexibilidad y versatilidad que presenta como principios el poder aéreo, ya que con la retoma de Tarapacá y su posterior y ágil movimiento a Güepí, la aviación militar colombiana demostró su "capacidad de concentrar la fuerza en cualquier lugar y atacar cualquier faceta del enemigo" (Fuerza Aérea Colombiana, 2013, pp. 74). De allí que el asedio sobre tal localidad peruana generara una plata- forma persistente al tiempo en el interior de la institución, por motivo que en esos días la aviación militar colombiana supo "adaptarse y permitir al comandante modificar los planes de acuerdo con los nuevos escenarios del campo de batalla" (Fuerza Aérea Colombiana, 2013, pp. 62-63).

\section{Referencias}

Boy, H. (2009). Una historia con alas. Bogotá, Colombia: Fuerza Aérea Colombiana.

Braudel, F. (2006) La larga duración. Revista Académica de Relaciones Internacionales, (5), 1-36.

Di John, J. (2010). Conceptualización de las causas y consecuencias de los Estados fallidos: una reseña crítica de la literatura. Revista de Estudios Sociales, (37), 46-86.

Forero, O. (1994). 75 años en los cielos patrios. Bogotá, Colombia: Fuerza Aérea Colombiana.

Fuerza Aérea Colombiana. (2013). Manual de Doctrina Básica Aérea y Espacial (MADBA). Cuarta edición. Bogotá. https://cdn. fac.mil.co/sites/default/files/manual_de_doctrina_basica_ aerea_y_espacial_mabda_fac-0-e_publico.pdf

Fuerza Aérea Colombiana. (2014). V. El conflicto fronterizo. Bogotá. Recuperado de https://www.fac.mil.co/v-el-conflicto-fronterizo

Goberna, J. (2003). Fernand Braudel, la civilización y la larga duración. Cuadernos de Estudios Gallegos, 50(116), 213-255.

Losada, F. (2014). Poder aéreo como herramienta de coerción. Taktika, 5(9), 12-19.

Marín, A. Esquivel, R., Castiblanco, C., Garzón, D., Castrillón, J., Cotrina, N., Santos, M., Echeverry, A., García, J., Barón, L., Gómez, J., Tiuso, A., Benavides, E., Guzmán, A., Jaimes, G. (2017). Victorias desde el aire: la Fuerza Aérea Colombiana y el término del conflicto armado, (p. 664). Segunda edición. Bogotá: Grupo Editorial Ibáñez.

Palacios, M., y Safford, F. (2002). Colombia. País fragmentando, sociedad dividida. Su historia. Bogotá, Colombia: Editorial Norma.

Peña, Y. (2015). De la subordinación a la autonomía: la profesionalización militar en la construcción de la aviación militar colombiana. 1920-1936. (Tesis de maestría). Bogotá: Pontificia Universidad Javeriana.

Villalobos, J. (1993). Historia de las fuerzas militares. Fuerza Aérea. Bogotá, Colombia: Planeta Colombiana Editorial S. A. 
